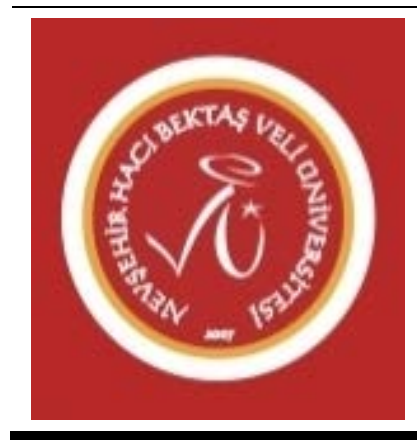

Nevşehir Bilim ve Teknoloji Dergisi

dergi web sayfası: http://dergipark.gov.tr/nevbiltek

Makale Doi: 10.17100/nevbiltek.424912

Geliş tarihi: 18.05.2018 Kabul tarihi: 23.09.2018

\title{
Endüstriyel Üretimde Döngüsel Çevre Politikaları
}

\author{
Hüseyin CÜCE \\ Nevşehir Üniversitesi, Mühendislik Mimarlık Fakültesi, Çevre Mühendisliği Bölümü, Nevşehir \\ ORCID ID: 0000-0002-3590-681X
}

Öz

Çeşitli endüstriyel alanlarda yapılmış çevresel analizler göstermektedir ki, atık maddeler, hacim ve kompozisyon bakımından farklı özelliklere sahip olsalar da genellikle az veya hiç arıtım yapılmaksızın deşarj edilmektedirler. Gelişmiş ülkelerin pek çoğunda, kirlilik kontrolü (boru sonu arıtım teknolojileri) üzerine odaklanan klasik çevre koruma yaklaşımlarının etkili bir çevre yönetimi olmadığı anlaşıldığından yeni yaklaşım ve teknikler benimsenmiştir. Hammadde, üretilen ürün ve oluşan artıkların tümü için bütünleşmiş bir yönetim uygulamak, kaynak tüketiminin ve atık minimizasyonunun etkin olarak tasarlandığı kirlilik önleme yaklaşımları ile mümkün olabilmektedir. Bu hedeflere ulaşmak için temiz üretim ve benzeri çevre dostu teknikler uygulanmalıdır. Endüstride temiz üretim, hammaddenin bir ürüne dönüştürülüp nihai bertarafina kadar ürün ömrü boyunca meydana gelebilecek olumsuz çevresel etkileri önler veya en aza indirir. Bu kapsamda önleyici çevre yönetimi ve temiz üretim uygulamaları giderek önem kazanmış olup çeşitli endüstrilere ihtiyaç duydukları desteği sağlamak üzere ulusal ve uluslararası kuruluşlar tarafindan çok sayıda program ve proje yürütülmektedir. Bu çalışmanın amacı, endüstride temiz üretim odaklı yaklaşımlar ve döngüsel çevre politikalarının araştırılması, ayrıca verimlilik stratejilerinin değerlendirilmesidir.

Anahtar Kelimeler: Çevre yönetimi, Temiz üretim, Kirlilik önleme, Endüstriyel ekoloji, Döngüsel çevre

\section{Circular Environmental Policies in The Industrial Production}

\begin{abstract}
Environmental analyzes carried out in vary industrial areas show that although waste materials have different properties in terms of volume and composition, they are usually discharged with little or no treatment. In many developed countries, it is understood that the classical environmental protection approach which focuses on pollution control (end of pipe treatment technologies) is not an efficient environmental management, so new approaches and techniques have been adopted. Implementing an integrated management for all of the raw materials, manufactured products and generated wastes may be possible with the pollution prevention approaches that resource consumption and waste minimization are effectively designed. Cleaner production and similar environmentally friendly techniques must be applied to achieve these goals. The cleaner production principle in the industrial sector prevents or minimizes the adverse environmental effects that can occur during the life of the product, from the raw material to the final disposal. In this context, preventive environmental management and clean production practices have become increasingly important, and a number of programs and projects have been carried out by national and international organizations to provide the support that various industries need. The aim of this study is to investigate the clean production-oriented approaches and cyclical environmental policies of the industry, as well as to evaluate productivity strategies.
\end{abstract}

Keywords: Environmental management, Cleaner production, Pollution prevention, Industrial ecology, Circular environment 


\section{Nevşehir Bilim ve Teknoloji Dergisi (2018), 7(2) 111-122}

\section{Giriş}

Endüstri geçmişte ve şu anda çevre kirliliğine neden olan en önemli faktörlerden olmuştur. Endüstrileşmenin çevre üzerindeki etkisi, dünyadaki nüfus artışının yol açtığı tüketim patlaması, doğal (yenilenemez) kaynakların hızla tükenmesi, çevre kirliliğinin dünyadaki doğal dengenin ve ekosistemin bozulmasına yol açması ve canlılar üzerindeki zararlı etkilerinin giderek artmasını beraberinde getirmiştir. Bu durum karşısında endüstriyel faaliyetlerden kaynaklanan olumsuz tüm çevresel etkilerin kaynakta önlenebilmesi veya azaltılabilmesi yönünde küresel düzeyde adımlar atılmış ve çevresel hassasiyet açısından endüstrilere pek çok sorumluluk yüklenmiştir. Çevre sorunlarının ağırlaşmasının temelinde yatan sorunun önemli bir bölümünü, çevreye yönelik yatırımların çok yüksek maliyetli olması oluşturmaktadır. Endüstriyel faaliyet sonucu oluşan atık miktarlarının ve arıtım maliyetinin sürekli olarak artması ile alıcı ortam deşarj standartlarının, kamuoyunda yükselen çevre bilincine paralel olarak, sürekli düşürülmesi, ürün ve hizmet üreten kurum ve sektörleri bu sorunun daha ucuz çözüm yollarını aramaya yöneltmiştir. Daha sonraları bu süreci, üretim ve hizmet sektörlerinde verimliliğin arttırılması, üretim için kullanılan hammaddelerin çevreye daha az zararlı olanlar ile değiştirilmesi, üretim ve kullanım sürecinde gerekli olan su ve enerji ihtiyaçlarının düşürülmesi gibi döngüsel çevre politikaları ve bütünleşmiş atık yönetim yaklaşımları takip etmiştir. Diğer taraftan, giderek genişleyen bir küresel pazar ve enformasyon teknolojisindeki patlama da endüstri üzerindeki sosyal baskıyı arttırmakta ve endüstrilerin her gün "daha yeşil endüstri” olma zorunluluğunu getirmektedir [1-4].

Araştırma ve uygulama çalışmaları geliştikçe, sürdürülebilir üretimi hedefleyen endüstriyel çevre yönetiminde bütünsel önleyici yaklaşım ve çevre sistemleri arasında doğal bir hiyerarşi oluşmaktadır. Son yıllarda dünya çapında yapılan bu çalışmaların ortak hedefi, ‘önleyicilik’ ve ‘eko-verimlilik' ilkeleri çerçevesinde oluşturulmuş çevre yönetim sistemleri ile davranışsal, yönetsel ve teknolojik değişikler aracılığıyla sanayinin çevresel etkilerinin azaltılmasıdır. Günümüzde atıklar ile mücadele edebilmek, çevreyi koruyabilmek ve endüstriyel üretim ve gelişimde sürdürülebilirliği sağlayabilmek için çevre yönetim sistemleri geliştirilmektedir. Kavramsal, yöntemsel ya da stratejilerden kurulu hedef

odaklı kararların alınması sürecinde kullanılan güncel çevre politikaları arasında; Yeniden Kullanım/Kazanım/Üretim/Dönüştürme, Temiz üretim için yeni ve yeşil teknoloji kullanımı, Yaşam Döngüsü Analizi, Çevre için Tasarım vb. yaklaşımları öne çıkmaktadır.

Temiz üretim ve yeni çevre dostu teknoloji kullanımı da özellikle son 20 yılda atıklar ile mücadelede kullanılan bir kavram olarak yaygınlaşmaktadır. Bu yaklaşımın temelinde, üretim sırasında oluşabilecek atıkları daha ortaya çıkmadan azaltmayı hedefler ve bu yönüyle diğer birçok çevre kirliliği ile mücadelede yöntemi arasında bir adım öne çıkar. Ürünlerin temiz teknoloji kullanılarak, çevre tahribatında sıfır kirlilik anlayışı ile üretilmesini ya da daha az atık üretilerek ürün imal edilebilmesini sağlayacak çözüm yöntemlerini sürece dahil ederek endüstriye hem ekonomik hem ekolojik katkılar sağlar. Bu tür yaklaşımların benimsenmesiyle birlikte büyük çapta kurumsallaşmış sanayi dallarında, üretim esnasında veya sonrasında muhtemel atıklar daha üretim yapılmadan tasarım aşamasında göz önünde bulundurulmakta ve bunların çevreye olan bozucu etkileri azaltılmaya çalışılmaktadır. Bununla birlikte, halen pek çok sanayi dalında, atık bertarafı ve atıksu arıtımında boru sonu teknolojileri kullanılmakta, atıkların boşaltıldığı, atıksuların alıcı ortamlara deşarj edildiği noktasal kaynaklarda baca ağzına bir filtre bağlamakla atıkların arıtılabileceği sanılmaktadır. Oysaki, filtrasyon ancak bir yere kadar çevrenin kirletilmesini önleyebilmektedir ve bakımları ihmal edilen filtreler sebebiyle arıtma işleminin minimal düzeyde kaldığı izlenmiştir. Boru sonu arıtım yaklaşımı, süreç ölçümü yapan şirket yöneticilerinin ve uzmanlar tarafından uygulanan bilinçli eylemleri içermesine rağmen, tam olarak işgücünden alınabilecek faydaları ve bağlantıları içeren eylemlerin sorumluluk düzeyini yükseltemez. Dünyada bu teknolojiler için çok yüksek maliyetli yatırımlar yapılmakta, bazen kurulan tesisler tam verimle çalıştırılamamakta, bu da hem kaynak 
israfına sebep olmakta hem de sanayicilerin arıtım için yaptığı yatırımın yanlış olduğu kanısına varmasına neden olmaktadir [5 ve 6].

Söz konusu kavramların ortak hedefi çevreye duyarlı üretim olmakla birlikte hali hazırda bir karmaşaya da yol açabilmektedir. Uygulayıcı endüstrilerde hangi yaklaşımın istenilen ve beklenen hedeflere daha hızlı ve sürdürülebilir biçimde ulaşabileceklerini gösteren döngüsel yapıda çevre politikası veya bütüncül politikalara ihtiyaçları vardır. Bu kapsamda bu araştırmanın ilk bölümünde, çevre yönetimde döngüsel nitelikte sürdürülebilir üretimi odağında tutan Temiz Üretim kavramına değinilerek benzeri çevre politikaları ve yaklaşımların tanımlamaları ve gelişim süreci hakkında bilgilere yer verilmiştir. Sonraki bölümlerde endüstriyel faaliyetlerin bu tür sistemlere olan ihtiyacı değerlendirilmiş ve firmaların rekabet, verimlilik ve büyüme stratejilerinde çevreye olabilecek etkileri azaltan örnek bir tasarım yaklaşımı üzerinde tartışılarak temiz üretim odaklı döngüsel çevre politikalarının uygulamadaki zorlukları incelenmiştir.

\section{2. Çevre Yönetiminde Temiz Üretim ve Döngüsel Çevre Kavramı}

Endüstriyel çevresel etkilerin önlenebilmesi için döngüsel bir yaklaşımla uygulanabilecek en iyi tekniklerin odağında “Temiz Üretim” prensipleri yer almaktadır. Temiz Üretim, kaynakta emisyonlara engel olmak ve organizasyonların çevre performansı gelişimini devamlı kılmak için başlangıç teşkil eden bir stratejidir. Temiz üretim açısından çevre problemlerinden kurtulmada çözüm aramadan daha çok engel olma düşüncesi odak nokta olmalıdır. Tesislerin sürdürülebilir çevresel gelişim sağlaması için müşterek çabaları harekete geçirerek, süreç, ürün ve hizmet verimliliğini arttırmayı, doğaya zararı azaltmayı amaçlayan temiz üretim kavramı; ne tür atık ve emisyonlar üretilmektedir, atık ve emisyonlar niçin üretilmektedir, hangi maddeler kaybolmaktadır, kayıplar nasıl önlenebilir, bu atık ve emisyonların maliyeti nedir, iyileştirme olasılı̆̆ı var mıdır ve varsa nerelerdedir gibi sorulara cevap arar [7 ve 8]. Üretim sürecinden faydalı bir ürüne dönüşemeden geçip atık haline gelen hammaddeler ile su ve enerji gibi temel üretim girdilerinin daha etkin kullanımı sonucu kayıpların önlenmesi ve böylece çevresel etkilerin azaltılması (eko-verimlilik) temiz üretim odaklı çevresel yönetim hiyerarşisinin (Şekil 1) temelini oluşturmaktadır. Birleşmiş Milletler Çevre Programı, temiz üretimi “üretim süreçlerine, ürün ve hizmetlere sürekli olarak bütünsel ve önleyici bir çevre stratejisi uygulanması ile insanlar ve çevre üzerindeki risklerin azaltılması” olarak tanımlamıştır. Faaliyetleri sonucunda belirli bir kirliliğin oluşmasından sorumlu olan tüm işletmeler, bu yaklaşımı benimseyip uygulayarak bu özeliklerini tersine çevirebilirler [9].

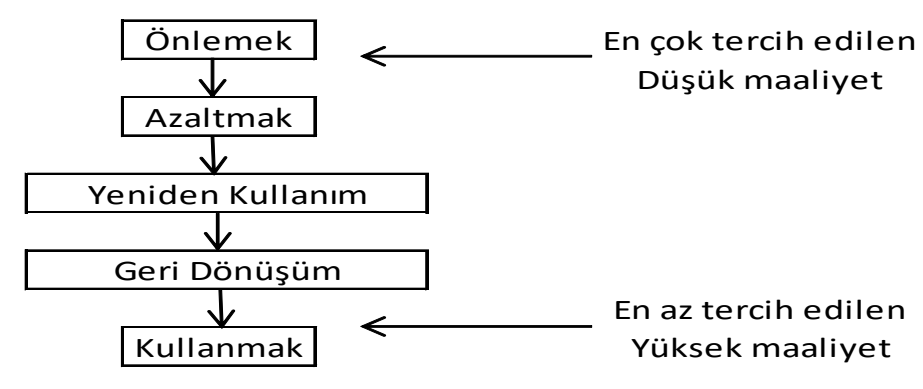

Şekil 1. Temiz Üretim Odaklı Çevre Yönetim Hiyerarşisi

Bu hiyerarşide atığın oluşumunu önleyen ya da miktarını azaltan yöntemler daha önceliklidir. Atık bertarafı ve geleneksel kirlilik kontrolü yöntemleri ise tepkisel yaklaşımlar olarak değerlendirilmekte olup önleyicilik ve ekoverimlilik ilkelerine uyum sağlamadıklarından en alt basamakta yer almaktadırlar.

\subsection{Temiz Üretim Odakı Döngüsel Çevre Politikaları}


Temiz üretim ve döngüsel çevre stratejisi ile doğrudan veya dolaylı ilgisi olan bazı farklı terminolojilerin karşılaştırmalı olarak gösterimleri Şekil 2'de verilmişstir.

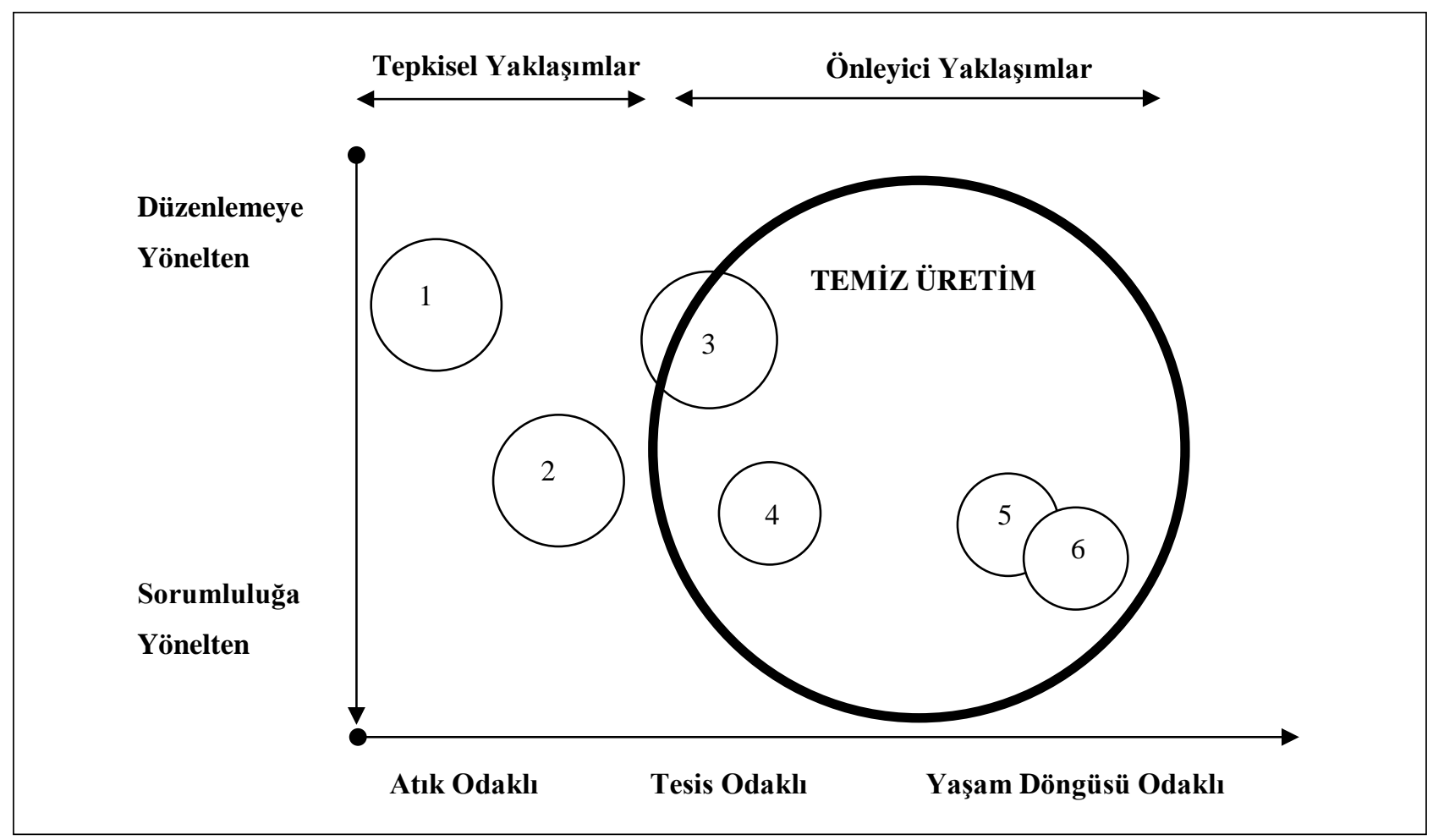

Şekil 2. Temiz Üretimle Doğrudan veya Dolaylı Olarak İlgisi olan Farklı Terminolojiler [10;www. unido.org/cp (Guidance Manual)], (Sekilde; 1-Boru-sonu teknolojisi, 2-Geri dönüşüm, geri kazanım ve yeniden kullanım, 3-Atık minimizasyonu, 4-Kirlilik Önleme, 5-Çevre için Tasarım, 6- Ekoverimlilik yaklaşımlarını simgeler.)

\subsubsection{Kirlilik Önleme}

Çevre kirliliğine bir bütün olarak bakıldığında, kirliliğin ortadan kaldırılması yerine kirlenmenin önlenmesi en akılcı çözüm olarak ortaya çıkmaktadır. Sonucunda, atık miktarını azaltan ya da tam anlamıyla gideren üretim süreçleri ve stratejilerini tanımlamada kullanılan bir terimdir. ABD Çevre Koruma Kurumu (EPA) tarafından "kirlilik önleme” kavramı; her türden tehlikeli madde ve kirleticinin doğrudan alıcı ortamlara verilmesi ya da geri dönüştürme, arıtım ve nihai depolama süreçleri öncesi atıklara karışmasını önleyen/azaltan, atık maddelerin deşarjı kaynaklı halk sağlığı ve çevresel zararları önleyen/azaltan, endüstriyel hammaddelerin verimli kullanılması veya doğal kaynakların etkin yönetimi ile atık miktarını azaltan ya da yok eden herhangi bir etkinlik olarak tanımlanmaktadır.

Kirlilik önleme, aşağıdaki 5 strateji üzerine kurulmuş bir görevdir [11 ve 12]:

- Uygulanabilir olduğunda kirliliği kaynağında azalt

- Yerinde kazan ve tekrar kullan

- Bir tesiste çevre dostu bir yöntemle geri dönüştür

- Çevre dostu yöntemle kirliliği arıt

- Son çare olarak bertaraf et veya doğaya bırak

Kirlilik önleme kavramı, donanım veya teknoloji değişikliklerini, ürünlerin yeniden tasarlanmasını, hammadde değişimini, üretim ortamının iyileştirilmesi ve düzenli bakım çalışmalarını, eğitim ve envanter kontrolü çalışmalarını kapsamaktadır. Dolayısıyla kirlilik önleme, değerli kaynakların korunması için sürdürülebilir yaklaşımların uygulanması ve atık üretiminin azaltılması için endüstriyel proseslerin modifikasyonunu birlikte içerir. Çoğu zaman kirlilik önleme ve temiz üretim terimleri birbirleri yerine kullanılsa da, kullanımı daha çok ABD'de yaygın olan kirlilik önleme kavramı 
üretim süreçlerine odaklıdır. Ürün tasarımı bir bileşeni olsa da, kirlilik önlemede öncelik daha az tehlikeli kimyasal kullanımı ve atık oluşumunu kaynağında azaltmaya verilir. Bu bağlamda kirlilik önleme temiz üretimin bir alt basamağı olarak değerlendirilebilir [13-15].

\subsubsection{Atık Minimizasyonu}

Kirliliği önlemenin ilk adımlarından biri olan atık minimizasyonu, ilk kez 1984 yılında ABD tehlikeli ve katı atık değişiklikleri (HSWA) ile Kaynak koruma ve kurtarma yasası (RCRA) olarak sunulan ulusal bir politikadır. Üretilen veya daha sonra arıtılan, depolanan veya bertaraf edilen herhangi bir katı veya tehlikeli atığın azaltılmasını içeren bu politika, aynı zamanda toksik bileşenlerin miktarında azaltmayla birlikte geri dönüşüm ve genel hacim azaltma kavramlarını da içerir. Atık minimizasyonunda başarının sağlanabilmesi: Atık azaltma için özendirme, depolama ve belirli atıklar için hizmet bedeli ve vergilendirme, kompostlamayı teşvik etmek, Devletin yapım ve satın-alma politikaları, belirli ürünlerde sınırlama, Temiz üretim ve geri-dönüşümde mükemmel düzeyde merkezi gelişimin sağlanması yönünde girişimlerde bulunulmalıdır. Atık minimizasyonu, arıtılması ya da deşarj edilmesi gereken atıkların miktarının en aza indirilmesi anlamlarının yanında geri dönüşümü de içeren oldukça geniş bir terimdir. Kirlilik önleme ve atık minimizasyonu terimleri birbirleriyle etkileşim halinde olması gereken iki strateji olarak kendini göstermektedir [10 ve $11]$.

Üretim sürecinde ortaya çıkan ve sonradan arıtma, ayırma veya bertaraf etme işlemlerine tabi tutulması gereken tehlikeli atık miktarını mümkün olan en alt seviyeye indirmek demektir. İnsan sağlığına ve çevreye şu an ve gelecekte vereceği zararların en aza indirilmesi amacıyla tehlikeli atığın hacminin, miktarının ya da zehirliliğinin azaltılması için gerçekleştirilen her tür süreç optimizasyonu ya da geri dönüştürme çalışmaları atık azaltımı olarak tanımlanmaktadır. Atık minimizasyonu, kirlilik önleme ve temiz üretim çalışmalarının bir alt kümesini oluşturmakta ve kirlilik önleme direktifi'nde (1992) detayları verilmektedir. Satın alma ve tasarım süreçlerinde gerçekleştirilen ve toksik atık kaynaklarının azaltılması amacıyla yapılan çalışmalardan ayrı olarak bir üretim işlemi olarak ele alınmaktadır [16 ve 17].

\subsection{3. Çevre için Tasarım}

Bir ürünün negatif çevresel etkilerini, bilinçli bir tasarım yoluyla minimize etmek için ele alınan değerlendirme çabalarıdır. Eko-tasarım ve yeşil ürün tasarımı olarak da adlandırılır. Çevre için Tasarım (ÇITT-DfE) programı, işletme kararlarını alırken çevre ve sağlık açısından entegrasyonu sağlamak için doğrudan endüstrilerle yapılan gönüllülük esasına dayanan bir çalışma programıdır. ÇİT, aynı zamanda 1980’lerin sonunda ilk kez şirketlerin adapte ettiği, ürün ve süreç tasarımında kalite için tasarım düşüncesini kapsayan bir yaklaşımdır. ÇíT, tasarım süreci içerisinde yer alan ulusal yönetmelikleri göz önünde tutmayı, insan sağlığı ve güvenliğini, tehlikeli madde minimizasyonunu, ayırma, geri kazanma, geri dönüşüm ve bertaraf etmeyi de içine alan bir yapıdadır [18].

Çevresel açıdan güvenilir ürün geliştirme (ÇEGÜ-ERPD), çevreye duyarlı üretim olarak ta bilinir, ürün geliştirme ve üretimin sayısız ve çok farklı aktiviteleri süresince hem çevresel etkileri hem de ekonomik amaçlar dikkate alınır. ÇEGÜ, enerjiyi etkin kullanan ve çevreye duyarlı ürünleri geliştirme çabaları olarak ele alınır. Ürünler, yaşam döngülerinin tüm basamaklarında (örneğin, ham madde ayrımı, üretim, montaj, dağıtım ve ürünün ömrünü tamamlaması) başından sonuna kadar çevresel etkilere yol açar. Bu çevresel etkileri minimize etmek için pek çok yol vardır. Çalışmalar, ürün tasarım aşamaları süresince ÇEGÜ için en büyük fırsatın oluştuğunu göstermektedir. Bu aşamalar süresince alınan kararlar ürünün çevresel etkisinin çoğunu belirler. ÇEGÜ ekstra çaba gerektirmesine rağmen, sadece çevreyi korumaz aynı zamanda kolektif seviyede belirlenmiş çevresel ilkelerin uygulanması için bir yol da sunar.

Yeniden montaj için Tasarım felsefesi de ÇİT kapsamında ele alınabilir. Ürünü oluşturan parçaların kullanım ömrü sonunda kolaylıkla parçalanıp demonte edilebilecek (sökülebilecek) ve başkaca amaçlar için yeniden kullanılabilir 
Nevşehir Bilim ve Teknoloji Dergisi (2018), 7(2) 111-122

elemanlar haline getirilebilecek şekilde tasarlanması ana hedeftir. Demontaj için Tasarım özellikle otomotiv ve mobilya endüstrisinin sıklıkla kullandığı bir yöntemdir. "Kolayca ayrıştırılabilme ve kazanılabilme", "Yeniden Dönüştürülebilme” bu felsefede kullanılan en önemli iki kriterdir. Buna göre, tasarlanan bir ürün için, kolayca geri dönüştürülebilecek, kazanılabilecek ve ayrıştırılabilecek malzemelerin seçilmesine özen gösterilir. Ayrıca ürünün kullanım ömrünün uzun olması, minimum süreç ve ham madde gereksinimi de malzeme seçiminde etkili olan faktörlerdendir [19].

\subsubsection{Eko-Verimlilik}

Eko-Verimlilik teknik bir çözümden öte, sanayide işçisinden üst yöneticisine kadar sahiplenilen ve temiz teknoloji ve tekniklere odaklanılan bütünleşmiş yönetim biçimidir. Üretim sürecinden faydalı bir ürüne dönüşemeden geçip atık haline gelen hammaddeler ile su ve enerji gibi temel üretim girdilerinin daha etkin kullanımı sonucu kayıpların önlenmesi ve böylece çevresel etkilerin azaltılması yaklaşımıdır. Kavramı ilk ortaya atan kurum olan Sürdürülebilir Kalkınma için İş Konseyi (WBCSD, 1992) “kullanılabilir ürün ve hizmetlerin arttırılmasıyla eş zamanlı olarak doğal kaynakların (hammadde, su ve enerjinin) kullanımının sürekli azaltılması” olarak tanımlamıştır. "Daha azla daha çok üret” ilkesiyle verimin arttırılmasını hedefleyen Eko-verimlilik prensibi, “çevresel problemlerin önemli bir kısmının kaynak kullanımındaki verimsizliklerden kaynaklandığı ve buna bağlı olarak çevreye daha duyarlı işleyişlerin, en azından belli bir noktaya kadar, ekonomik olarak da karlı olacağını” vurgulamaktadır [20-22].

Asya Verimlilik Organizasyonu (Asian Productivity Organization-APO) tarafından 1994'te "Yeşil Verimlilik” programı da, sürdürülebilir üretimin başarıyla gerçekleştirilebilmesinin sağlanabilmesinde adres olabilmek amacıyla başlatılmıştır [23].

\subsubsection{Endüstriyel Ekoloji (Simbiyoz)}

Frosch ve Gallopoulos [24] tarafindan 1989 yılında gündeme getirilmiş olan “Endüstriyel Ekoloji” ve “Endüstriyel Ekosistem” konseptleri, endüstriyel aktivitelerin doğal yaşam ve ekolojik sistemler ile benzerliğine dayanmaktadır. "Endüstriyel Metabolizma” kavramı da ilk olarak Ayres [25 ve 26] tarafından ortaya atılmış olup, hammaddenin ve enerjinin yanında insan gücünün de, nihai ürüne ve atığa dönüştürüldüğü prosesler bütünü olarak tanımlanmıştır. Bu tanım, endüstriyel ekolojinin sürdürülebilir üretime en yakın şekli olarak gösterilmiştir. Endüstriyel ekoloji; "madde ve enerji kaynaklarının endüstriyel sistemler içerisinde dönüşümünü sağlanması” ve "endüstri ile doğal ekosistem arasındaki ilişkilerin detaylandırılarak etüt edilmesi ve endüstriyel sistemlerde proses odaklı değişikliklerin gerçekleştirilmesi” ile daha sürdürülebilir bir endüstriyel sistemler bütünü oluşturulmasını hedefleyen düşünceler bütünüdür.

Endüstriyel ekoloji yaklaşımının amacı, doğal sistemlerin işleyişini analiz edip bu modeli insan yapımı sistemlerin tasarımına uygulayarak, sadece daha verimli değil aynı zamanda doğanın özelliklerine ve taşıma kapasitesine göre düzenlenmiş bir sanayileşme kalıbının üretilmesini sağlamak olarak özetlenebilir. Kavram, bir sanayi sisteminin çevresindeki diğer sistemlerden yalıtılmış olmadığını, doğal sistemlerle uyum içinde çalışması gerekliliğini vurgulamaktadır. Endüstriyel ekoloji, endüstri-ekonomi ve doğal sistemler arasındaki bağlantıların disiplinler arası çalışmasıdır, amaçtır. Hem endüstriyel sistemler içinde hem de bağlantılı olduğu doğal ekolojik sistemler arasındaki fiziksel, kimyasal ve biyolojik etkileşimlerin ve ilişkilerin sistem odaklı araştırılmasıdır. Endüstriyel ekolojide, malzemelerle (kütle) ve enerji kullanımında bir israf olmayacağı şekilde bir grup işletme organize olacaktır. Bir endüstriyel işletmenin atığı başka bir endüstri için hammadde olarak kullanılabilecektir. Eko-endüstriyel parkların oluşturulması da aynı zamanda büyük önem arz etmektedir. Bu oluşumlar, birbirleri arasında ham madde, atık madde ve enerji değişimi yapabilen endüstrilerin gruplar halinde bulunduğu ve böylece endüstriyel parkın net girdi-çıktısını azaltan oluşumlardır [27-29]. 
Bütünsel bir yönetim ve teknik program olan uygulamalı endüstriyel ekoloji;

- $\quad$ endüstriyel ekosistemlerin oluşturulması,

- $\quad$ endüstriyel girdi ve çıktıların doğal ekosistem kapasitelerine göre dengelenmesi,

- endüstriyel çıktıların demateryalizasyonu,

- endüstriyel süreçlerin ve hammadde kullanımının metabolik yollarının iyileştirilmesi,

- $\quad$ enerji kullanımının sistemik modelleri,

- $\quad$ endüstriyel ekoloji evrimi perspektifli uzun vadeli politikaların düzenlenmesi çalışmalarını kapsamaktadır.

Endüstriyel ekoloji yaklaşımı çerçevesinde daha sürdürülebilir bir endüstriyel sisteme yaklaşabilmek için genel ilkeler şöyle özetlenebilir:

- Yenilenemeyen kaynakların tek yönlü tüketimi ciddi şekilde azaltılmalı ve zamanla son bulmalıdır.

- Endüstriyel sistemlerin enerji ihtiyaçları da tamamen yenilenebilir kaynaklarla karşılanmalıdır.

- Doğal ve endüstriyel sistemler arasındaki etkileşimler doğal sistemlerde geri dönüşü olmayacak değişikliklere sebep olmamalidir.

- Beklenmedik şoklar karşısında işleyişlerinin aksamaması için endüstriyel sistemler çok çeşitli ve hem bireysel olarak hem de toplu halde güçlü olan sistemlerden oluşmalıdır [30 ve 31].

\subsubsection{Yaşam Döngüsü Analizi}

Endüstriyel bir ürün veya malzemenin, bütün yaşam döngüsü boyunca çevreye yaptığı etkileri sistematik biçimde değerlendirmek üzere kullanılan bir yöntemdir. Yaşam Döngüsü Analizi (YDA-LCA), işletmenin farklı fonksiyonel alanlarından çalışanları bir araya getirmekte, hammaddelerin satın alınmasından, üretime, geri dönüşüm süreçlerine ve atıkların yönetimine kadar uzanan geniş bir yelpazeyi kapsamaktadır. Yaşam döngüsü analizi, dört aşamadan oluşmaktadır. Amaçların belirlenmesi aşamasında bu çalışmanın amaçları ve kapsadığı alan ortaya konmaktadır. Envanter analizi aşaması, emisyonların, kullanılan enerji ve hammadde miktarının sayılara dökülüp teknik olarak analiz edilmesi çabalarını kapsamaktadır. Çevresel etki değerlendirmesi aşamasında, insanlar, ekosistem ve doğal kaynaklar üzerindeki potansiyel çevresel etkiler belirlenmektedir. İyileştirmenin ölçümü aşaması ise, bir ürünün/sürecin yaşamı boyunca iyileştirmelerin yapılıp yapılamayacağını belirlemek üzere çevresel etkilerin değerlendirilmesidir.

\subsubsection{Yeşil Kimya ve Yeşil Mühendislik}

İlk olarak Anastas ve Warner (1998) tarafından yayınlanan ve günümüzde ABD Çevre Koruma Ajansı (USEPA) programına alınan Yeşil Kimya ve yeşil mühendislik anlayışında temel prensipler 4 ilke etrafında toplanabilir. Bunlar; kimya ve teknoloji inovasyonu, kütle ve enerji verimliliği, toksisite ve devamlılığı, hammaddelerin yenilenebilirliği şeklindedir. Özellikle kimyasalların üretimi sürecinde yüksek oranlarda enerji tüketildiği ve bu miktarın azaltılmasında kaynak ve enerji verimliliğinin ön planda tutulması gerektiği aşikardır. Sürdürülebilir yeşil kimya ve mühendislik ilkelerini uygulamak, yeni kimyasal yollar ve kimyasal prosesler tasarlamak, reaktör ve speratörler seçmek anlamına gelir ve kişi şunlar için çabalamalıdır:

- Doğal kaynak tüketimini azaltmak, kaynak etkinliğini maksimuma çıkarmak

- Atığı engellemeye çalışmak; Tehlike ve kirliliği en aza indirmek ve yok etmek

- Kullanım süresi fikrini kullanarak sistemleri bir bütün olarak tasarlamak

Sonunda çeşitli stratejiler bizi başlangıçtan daha iyi, daha ucuz, daha hızlı ve daha temiz işlemler tasarlamaya yönlendirmelidir [32-34]. 


\section{Tartışma}

Çevresel şartlar geliştirilirken dikkate alınması ve çözüm önerilmesi gereken sorunların bazıları; Materyal sorunları (işleme, kullanım, uzaklaşıırma ile ilgili etkilerin miktarı), Enerji sorunları (kaynak, işleme vb. miktarı), Artık sorunu (Atığın türü, karakterizasyonu, çevresel akıbeti vb. gibi), Ekolojik faktörler (ekosistem etkileri ve ekolojik stres etkenlerinin türü), İnsan sağlığı ve güvenliği sorunları (risk altındaki popülasyon, toksikolojik karakterizasyon, kazalar) şeklinde özetlenebilir. Bu sorunların üstesinden gelebilmek ve çevresel etkiyi hesaba katan endüstriyel üretim sürecinde ürünün yaşam döngüsü sürecinde çözüm yaklaşımlarında düşünülen tüm faktörler, performans, maliyet, kültürel ve yasal tasarım gereksinimleri ile birleştirilerek ele alınmalıdır. Endüstriyel faaliyetler sonucu oluşabilecek çevresel etkileri azaltmak için genel bir tasarım yaklaşımının esas ögeleri Şekil 3'deki diyagramda verilmektedir.

Eko-verimlilik ve temiz üretim terminolojileri hemen hemen benzer anlam taşıllar. Ayrıldıkları temel nokta, ekoverimlilik, ekonomi odaklı fayda-maliyet konularından yola çıkarak çevresel performansa katkıda bulunurken Temiz üretim, çevre odaklı endüstriyel verimi arttırma konularından başlayarak ekonomik faydalar sağlamaktadır. Bakanlıkça yayınlanan kılavuza (2014) uygun olarak Eko-verimlilik uygulamalarını gerçekleştiren işletmeler; rekabetçi baskılara daha atak bir şekilde yanıt verebilecek, müşteri ihtiyaçlarını anlayabilecek, işçi sağlığı ve iş güvenliği için gerekli koşulları sağlayabilecek, aynı zamanda da çevreyi koruyabilecektir. Hem ekolojik hem ekonomik verimliliğin aynı anda hayata geçirilmesi, alınacak önlem ve uygulanacak verimlilik yöntemleriyle atık minimizasyonunun yanı sıra üretim ve hizmet maliyetlerini de büyük oranlarda düşürülmesi olasıdır. Bunu için ilkenin satın alma, üretim süreçleri ve atık yönetiminde bir bütün olarak uygulanması gereklidir. Ürün ve proses tasarımı birleşik yapıda olmasına rağmen, proses iyileștirme çabaları genellikle ürün gelişimi dışında gerçekleştirilmeye çalışılır.

Türkiye Teknoloji Geliştirme Vakfı (2014), yakın gelecekte, temiz üretim kavramının çevre yönetimi ve verimlilik ile ilgili çalışmalarla çok daha sarmal bir yapı haline geleceğini öngörmektedir. Bu konuda geliştirilen uluslararası projeler, düzenlemeler, ülkesel bazda alınan önlemler, teşvikler, sürdürülebilir kalkınmanın önceliklerinden birinin temiz teknoloji kullanmak ve temiz üretim proseslerine sahip olmaktan geçtiğini göstermektedir. Ülkemizde KOBİ ve üst düzey nitelikte büyük işletmelerin pek çoğunda halen köklü ve yapısal çevre yönetimi anlayışları gelişmemiş düzeyde olmakla birlikte çevreye duyarlı çalışmaların eko verimlilik boyutuyla değil sanayi vizyonu amaçlı sürdürülmekte olduğu bilinmektedir. Eko verimliliğin ülkemizdeki işletmeler tarafindan daha aktif kullanımı için "eko düşünce" kavramı gibi eğitim ve inovasyon noktasında kurumsal iletişim uygulamalarının yaygınlaştırılması gerekmektedir. 


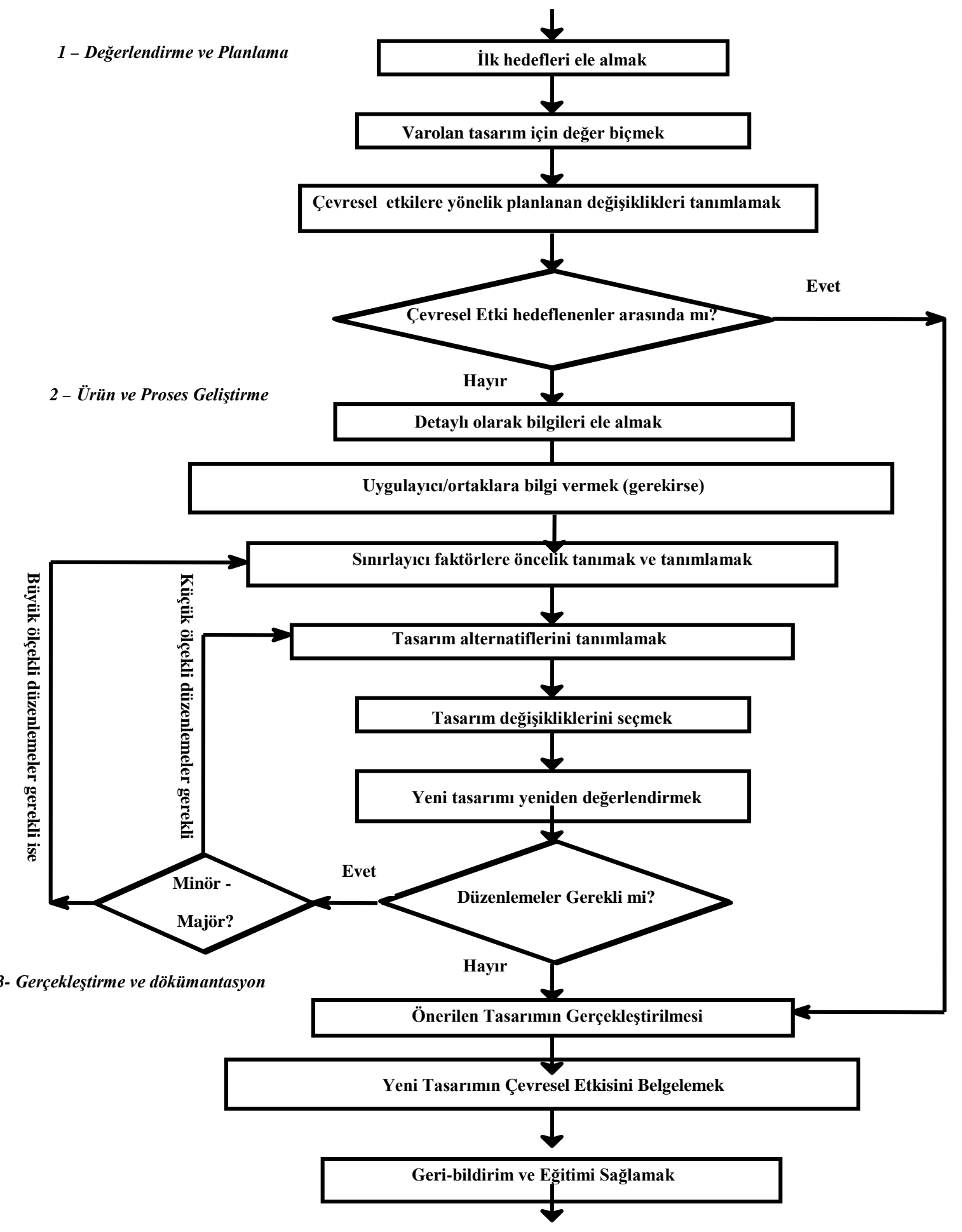

Şekil 3. Çevresel Etkiyi Azaltmak için Genel bir Tasarım Yaklaşımı [35, http://www.srl.gatech.edu/]

\section{Sonuç}

Araştırma ve uygulama çalışmaları geliştikçe, sürdürülebilir üretimi hedefleyen endüstriyel çevre yönetiminde bütünsel önleyici yaklaşım çerçevesinde kullanılan yöntemler arasında doğal bir hiyerarşi oluşmaktadır. Bu hiyerarşide atığın oluşumunu önleyen ya da miktarını azaltan yöntemler daha önceliklidir. Çevreyi ve insan sağlığını negatif olarak etkileyen artıkların ve emisyonların yok edilmesi sanayiciye ekstra bir yük getirmektedir. Bu da sanayicinin, bu işlemlerden kaçmasına ya da minimum düzeyde önlem almasına neden olmaktadır. Boru sonu arıtım yaklaşımı ile filtreleme benzeri kısıtlı mühendislik çözümlerinin yerine temiz ve yeni teknolojiler kullanılarak, sıfır atık prensibi ile 
üretmeye çalışmak, çevreyi koruma ve sürdürülebilir olarak yönetmede kullanılabilecek en kestirme ve en akılcı yol gibi gözükmektedir. Atıkların minimizasyonu için yapılacak çalışmalar, endüstriyel kaynakların etkili olarak kullanılmasını, su ve enerji gibi çokça tüketilen kaynakların büyük ölçüde tasarrufunu da sağlayabilecektir. Temiz üretim ve çevre dostu teknoloji kullanımının daha etkin olabilmesi için yeniden kazanım (arıtılmış atıksuların geri kazanımı gibi) veya endüstriyel ekoloji (simbiyoz) teknikleri ile birlikte kullanılması da düşünülmelidir.

Sonuç olarak, endüstriyel üretim yapan şirketler, çevreye duyarlı ürünleri meydana getiren tasarımcılara yardımcı olan araçları geliştirmek için epey çaba harcarlar. Bu araçlar, yaşam döngüsü değerlendirme (YDA) ve Çevre için Tasarım (ÇİT) araçları gibi ürünün üretimi sürecinde çevresel etkileri en aza indirmek için geliştirilmiş önleyici terminolojilerdir. Bu araçlar, ürünün yaşam döngüsü tamamlanana kadar ürünle ilgili çevresel etkileri değerlendirmede temel bir yöntem-bilim ortaya koyar. Çevresel yönetim entegrasyonu çerçevesinde bu tür terminolojiler, proseste değişiklik yoluyla (iyileştirilmiş proses düzeni) ve/veya endüstriyel ürün tasarımını yenileme yoluyla verimliliği arttırırken arıtım maliyetlerini azaltan ve tasarım kararını destekleyen araçlardır.

\section{Kaynaklar}

[1] Demirer, N. G., “Kirlilik Önleme Yaklaşımının Temel Prensipleri”, Çevre ve Mühendis, TMMOB Çevre Mühendisleri Odası, Ankara, 2003, sayı:25, s.13-20.

[2] Demirer, N.G., "Temiz Üretim/Kirlilik Önleme Kavramı ve Çevre Mühendisliği Eğitimi”, Çevre Mühendisleri Odası, IV. Ulusal Çevre Mühendisliği Kongresi, Mersin, 2001.

[3] Atımtay, T.A., "Temiz Ürünler ve Temiz Prosesler Konusunda Avrupa'daki Son Gelişmeler”, Çevre Mühendisleri Odası, IV. Ulusal Çevre Mühendisliği Kongresi, Mersin. 2001.

[4] Visvanathan, C., Kumar S., "Issues For Beter İmplementation of Cleaner Production in Asian Small and Medium İndustries", Journal of Cleaner Production, 7, 1999, 127-134.

[5] MOED, “Minimisation Opportunuties Environmental Diagnosis”, Regional Activity Centre for Cleaner Production (RAC/CP), Spain, http//www.cipn.es, 2000.

[6] Kaya, M. Prof. Dr., Temiz Üretim, Teknoloji Araştırma Merkezi, Osmangazi Üniversitesi, Eskişehir, 2000. http://ogu_tekam.sitemynet.com/yazilar2/TEKAM_27.htm.

[7] Fresner J., "Cleaner production as a means for effective environmental management", Journal of Cleaner Production, 1998, Vol. 6, 171-179.

[8] C1lız N., Daylan B., Baydar G., "Sürdürülebilir Üretim ve Tüketim Yayınları-II, Temiz Üretim” Ankara, Çevre ve Şehircilik Bakanlığı, 2011

[9] Ohio EPA Office of Pollution Prevention. 1993. Ohio Pollution Prevention and Waste Minimization Planning Guidance Manual.

[10] Guidance Manuel, "How to Establish and Operate Cleaner Production Centres", Cleaner Production and Environmental Management Branch, UNIDO, www.unido.org/cp, Production and Consumption Branch, UNEP, www.uneptie.org/cp, 2004.

[11] Hanrahan G., 2013. Key Concepts in Environmental Chemistry (Çevre Kimyasında Temel Kavramlar: Problemler ve Çözüm Notları İlaveli) 1. Basımdan Çeviri (Ed. İsmail Toröz), Nobel Yayın Evi, Ankara, 393s.

[12] Habicht F. H., 1992. U.S. EPA, memo EPA Definition of Pollution Prevention. May 28, 1992. Washington, D.C.

[13] Hilson G., 2003. Defining “cleaner production” and “pollution prevention” in the mining context, Minerals Engineering, 16:305-321.

[14] Bishop, P. L., "Pollution Prevention: A New Paradigm For Engıneering Education", Water, Air and Soil Pollution, Kluwer Academic Publishers, Netherlands, 2000, 123: 505-515.

[15] Halkman, K. A., Atamer, M., Ertaş, H. A., Doç. Dr., "Endüstri ve Çevre İlişsileri”, Ziraat.Mühendisleri Odası, Türkiye 5. Teknik Kongresi, Ankara. 2000. 
[16] Gümüşel, D., “Kobilere Yönelik Çevre Yönetimi Araçları: Delta Eko-Verimlilik Programı Örneğgi”, Çevre Mühendisleri Odası, V. Ulusal Çevre Mühendisliği Kongresi, Ankara. 2003.

[17] Hamner, B., "What is the Relationship Between Cleaner Production, Pollution Prevention, Waste Minimization and ISO 14000?”, I. Asya Kimya Sanayinde Temiz Üretim Konferansı Bildirgesi, Tayvan, 1996.

[18] Fitzgerald D.P., Herrmann J.F., , Sandborn P.A., Schmidt L.C., 2005. Beyond Tools: A Design for Environment Process, International Journal of Performability Engineering Vol. 1, No. 2, pp. 105-120

[19] Hemel C. G. V., Keldmann T., 1996, "Applying DFX Experiences in Design for Environment," Design for X: Concurrent Engineering Imperatives, Chapmann \& Hall, London, pp. 72-95.

[20] Kıyık G., 2012. Türkiye'de Eko Verimliliğe İşletmeler Nasıl Bakıyor? e-Journal of New World Sciences Academy Volume: 7, Number: 2.

[21] TTGV, 2010. Türkiye'de temiz üretim uygulamalarının yaygınlaştırılması için çerçeve koşulların ve Ar-Ge ihtiyacının belirlenmesi projesi - Sonuç raporu - Çevre ve Orman Bakanlığı.

[22] Mirata, M., “Temiz Üretimin de Ötesi... Endüstriyel Ekoloji İlkeleri ve Bölgesel Uygulamaları”, Çevre ve Mühendis, sayı:25, s.21-27, TMMOB Çevre Mühendisleri Odası, Ankara, 2003.

[23] UNEP, 2004. Cleaner Production (CP) Activities, Division of Tech. Industry and Economics. http://uneptie.org.

[24] Frosch R, Gallopoulos N. Strategies for Manufacturing. Sci Am 1989; 261: 144-150.

[25] Ayres RU. Industrial Metabolism In Technology and Environment. Washington: National Academy Press, 1989.

[26] Ayres RU. Industrial metabolism: Theory and policy. Tokyo: United Nations University Press, 1994.

[27] Jimenez-Gonzalez C., Constable D.J.,2016. Green Chemistry and Engineering (Yeşil Kimya ve Mühendislik: Pratik Bir Tasarım Yaklaşımı) 1. Basımdan Çeviri (Ed. Kontaş Aşkar T.), Nobel Yayın Evi, Ankara, 681s.

[28] Manahan S.E., 2004. Environmental Chemistry, 8th ed., CRC Press, Boca Raton, FL.

[29] Ayres R. U., 2004. On the Life Cycle Metaphor: Where Ecology and Economics diverge. Ecol. Econ., 48:425-438.

[30] Tibbs, H. (1992) Industrial Ecology-An Agenda for Environmental Management. Pollution Prevention Review, 167.

[31] Özkan A., Günkaya Z., Özdemir A., Banar M., 2017. Sanayide Temiz Üretim ve Döngüsel Ekonomiye Geçişte Endüstriyel Simbiyoz Yaklaşımı: Bir Değerlendirme, Anadolu Üniversitesi Bilim ve Teknoloji Dergisi B - Teorik Bilimler. DOI: 10.20290/aubtdb.332377

[32] Abraham M. A., Nguyen N., 2003. Green Engineering: defining the principles-results from the San Destin Conference, 22(4): 233-236.

[33] Environmental Protection Agency, Local Government Pollution Prevention Toolkit, USEPA Publication, 1998. http://www.cleanerproduction.com/misc/Pubs/CP

[34] Lozano, J.F., Lozano, R., Freire, P., Jimenez-Gonzalez, C., Sakao, T., Ortiz M.G., Trianni A., Carpenter A., Viveros T., 2018. New perspectives for green and sustainable chemistry andengineering: Approaches from sustainable resource and energy use,management, and transformation Journal of Cleaner Production, 172: 227-232

[35] Erişim Linki, http://www.srl.gatech.edu/ , Erişim tarihi: 19.12.2017

[36] TTGV, 2014. Sürdürülebilir Rekabetçilik için Temiz Üretim (EKOSKOP), Türkiye Tekonoloji Geliştirme Vakfi, TTGV - T/2014/05, ISBN-978-605-64392-1-6, ANKARA

[37] T.C. Bilim, Sanayi Ve Teknoloji Bakanlığı Verimlilik Genel Müdürlüğü, KOBİ’ler için Eko-Verimlilik Kılavuzu, Ankara, Korza Yayıncılık, ISBN: 978-605-4889-04-4 
Nevşehir Bilim ve Teknoloji Dergisi (2018), 7(2) 111-122

\section{Extended Abstract}

\section{Introduction}

Newly, environmental sensitivity has been increasing quickly. Both businesses to prove their sensitivity to the environment and to meet consumers demands in order to adopt environmentally sensitive production technologies by adopting cyclical environmental approaches. Thus, in order to achieve sustainable development, emphasis should be given to the creation and the promotion of environmentally sustainable products. In many developed countries, it is understood that the classical environmental protection approach which focuses on pollution control (end of pipe treatment technologies) is not an efficient environmental management, so new approaches (cleaner production, pollution prevention, eco-productivity, waste minimization) and techniques (life cycle assessment, industrial ecology design for environmental, green chemistry and green engineering) have been adopted. These approaches and techniques predominantly provide innovative and flexible solutions, but they can be transformed into proactive solutions to create a sustainable agenda for long-term environmental management. Despite these proactive environmental policies, industrial sectors have faced significant challenges in effecting extensive and sustainable changes to industrial activities and environmental protection practices.

This paper, after a short introduction to contents of the Clean Production-Oriented Circular Environmental Policies, focused upon comparing and contrasting the perspectives of these strategies. The circular environmental strategies that provide rational inventory control for production processes aim to reduce the risks on human health and environmental values and increase productivity. Also, this study is offered as a step towards scientification of circular environmental management.

The prominent cyclical environmental approaches, such as green engineering, involve reducing the use of energy and raw materials for production processes, reducing toxic substances, reducing negative externalities caused by the product life cycle, and environmentally sensitive actions for services.

Cleaner production, industrial symbiosis, green engineering and eco-efficiency are becoming a necessity for assessing and managing products and processes in the industrial activities. So, for the purposes of this identification: cleaner production can be used as a basis for assessing the processes in their early conceptual and design stages, industrial symbiosis can emerged as a self-organizing business strategy among firms that are willing to cooperate to improve their economic and environmental performance, green engineering can help in selecting appropriate chemical processes that can help modulate decision making while eco-efficiency can help evaluate environmental and economic issues for goods and services in industrial sectors.

\section{Method}

The Literature search was used as a research method. The study includes identifying and comparing cyclic environmental policies and industrial pollution prevention and control techniques.

\section{Results and Discussion}

In the study, firstly, the cleaner production methods and similar methodologies in the literature were informed about the scope of cyclical environmental policies. Implementation of cleaner production techniques provides many benefits including operating costs reduction, raw material reduction, waste reduction and risk reduction to humans and the environment, improved health and occupational safety and adaptation to environmental protection regulations. However, circular environmental management policies also involves strategic planning and decision making to determine best action; prescribing options and assessing their effects and consequences; and choosing the best treatment option, while taking into consideration legislation.

In the discussion and conclusion, secondly, an evaluation was made on how a general design approach should be implemented in order to reduce the environmental impacts that could result from industrial activities. Finally, it considers environmentally friendly technology as an environmental management tool for reducing environmental impacts, industrial production benefits for businesses, and is recommended for sustainable cleaner production. There are numerous examples of application of the deliberate drive to measure progress towards more sustainable cleaner production and green processes. In this context, preventive environmental management and clean production practices have become increasingly important, and a number of programs and projects have been carried out by national and international organizations to provide the support that various industries need. 